\title{
Targeting Vitamin D Deficiency to Limit Exacerbations in Respiratory Diseases: Utopia or Strategy With Potential?
}

\author{
Karen Maes $^{1}\left[\right.$ (1) Jef Serré ${ }^{1} \cdot$ Carolien Mathyssen $^{1} \cdot$ Wim Janssens $^{1} \cdot$ Ghislaine Gayan-Ramirez $^{1}$
}

Received: 13 May 2019 / Accepted: 18 July 2019 / Published online: 26 July 2019

(c) The Author(s) 2019

\begin{abstract}
Patients with respiratory diseases such as cystic fibrosis, chronic obstructive pulmonary disease, or asthma often experience an acute worsening of respiratory symptoms, termed exacerbations. Although the course of exacerbations is disease specific, they are mostly triggered by a respiratory infection. Exacerbations often require hospitalization and are an important cause of mortality. Treatments of exacerbations aim to minimize the negative impact and to prevent subsequent events. Despite many existing therapy options, many patients do not benefit from therapy and suffer from recurrent events. Vitamin D deficiency is a worldwide problem and is extremely prevalent in these patients. Vitamin D, known for its calcemic effects, also has immunomodulatory and anti-infectious actions and can therefore be a possible agent to treat or prevent exacerbations. This review will focus on vitamin D as a potential candidate to treat or prevent exacerbations in CF, COPD, and asthma.
\end{abstract}

Keywords Vitamin D · Lung · Exacerbations

\section{Pulmonary Exacerbations}

Chronic respiratory diseases such as cystic fibrosis $(\mathrm{CF})$, chronic obstructive pulmonary disease (COPD), and asthma are generally characterized as inflammatory airway diseases. All three are heterogeneous in both progression and underlying pathology. However, they share a common feature namely acute exacerbations of the disease that have dramatic effects on the health and well-being of the patients. Exacerbations often lead to frequent and prolonged hospital stays, rapid disease worsening eventually leading to increased mortality [1]. Definitions of acute exacerbations of chronic respiratory diseases vary according to the respiratory disease and exist based upon clinical findings. For cystic fibrosis (CF), the EuroCFCare Working group has recommended to use modified Fuchs criteria to define exacerbations of $\mathrm{CF}$ which include the need for additional antibiotic therapy and a recent change of at least two of the following criteria: change in sputum volume or color, increased cough, increased fatigue, malaise or anorexia, decrease in lung function by $10 \%$ or more, and increased dyspnea $[2,3]$. The

Karen Maes

karen.maes@kuleuven.be

1 KU Leuven, Leuven, Belgium
Global Alliance of obstructive lung disease defines COPD exacerbations as an acute event characterized by worsening of the patient's respiratory symptoms that is beyond normal day-to-day variations and leads to a change in medication [4]. The Global Initiative for Asthma defines exacerbations as an episode of progressive increase in shortness of breath, cough, wheezing, or chest tightness (or a combination), accompanied by decreases in lung function [5]. However, in all cases, the definition of exacerbation includes a subjective change in symptoms. Air pollution, some specific medication, smoking, chronic stress, and other triggers have been identified to cause exacerbations, but the most important trigger for exacerbations are respiratory infections caused by viruses or bacteria $[3,6]$. Pathogens enter the host by airborne transmissions (e.g., droplets or aerosols), replicate in the respiratory tract, and cause clinical worsening of symptoms (exacerbations). Common viruses infecting the human respiratory tract include the rhinovirus, the influenza virus, the respiratory syncytial virus (RSV), the parainfluenza virus or the adenovirus [7] but there are many others as well. Not only viruses but also bacteria, including Streptococcus Pneumoniae, Moraxella Catarrhalis, Haemophilus influenzae and with more sever disease also Staphylococcus aureus, and Pseudomonas aeruginosa, can be the cause of a respiratory infection [8]. The majority of exacerbations are treated with a combined regimen of antibiotics and systemic 


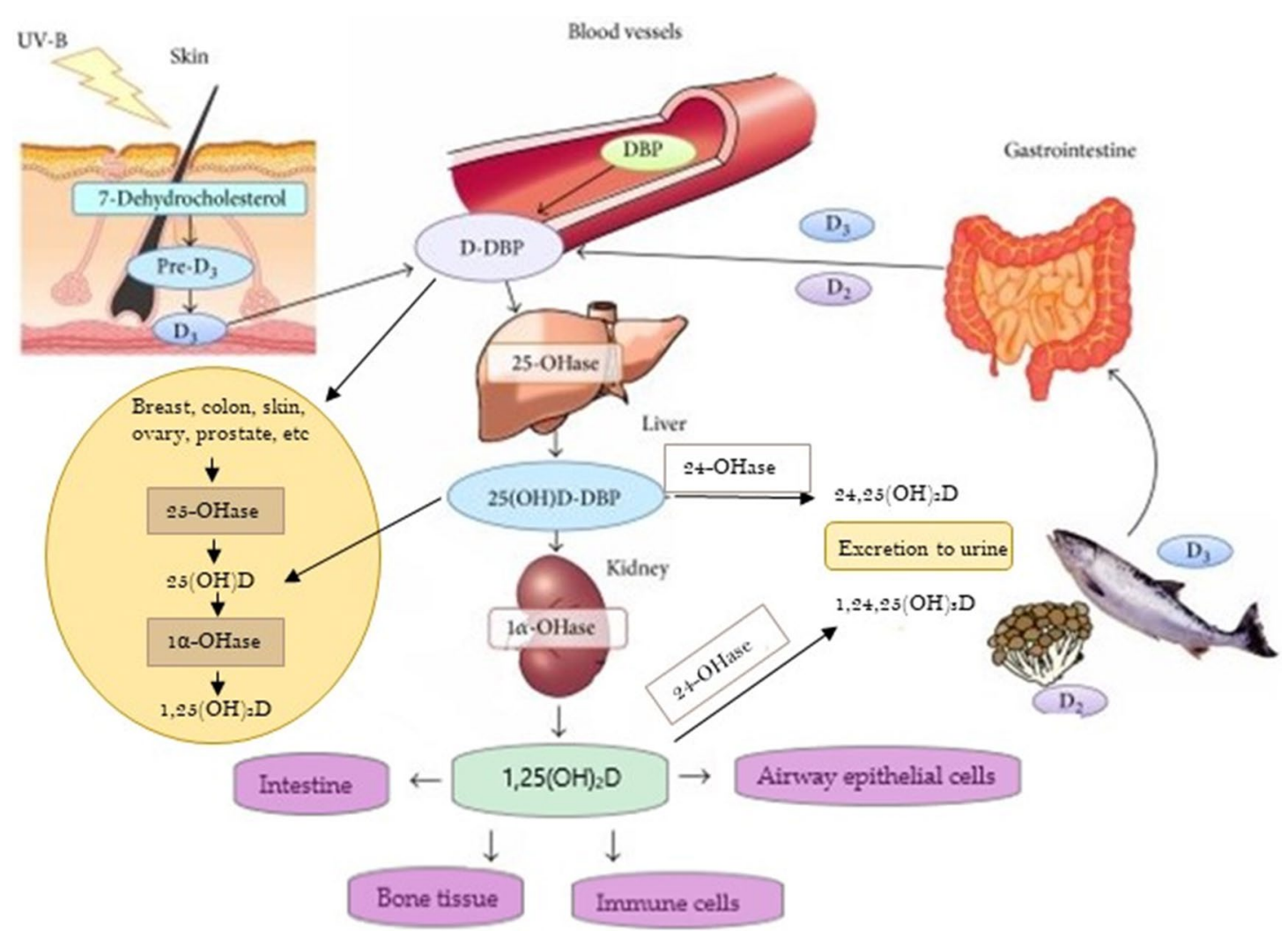

Fig. 1 Metabolism of 1,25(OH) $)_{2} \mathrm{D}$ (Adapted from Obi et al [122] under the terms of the CC Attributions 3.0 International (CC BY 3.0) license)

corticosteroids. Although these acute treatments are proven effective, many patients suffer from recurrent events despite optimal maintenance therapy. Therefore there is an urgent need for alternative strategies to treat or prevent exacerbations. The use of vitamin D as a strategy to reduce the frequency and severity of respiratory infections in respiratory diseases is an option that deserves further consideration.

\section{Vitamin D Metabolism and Mechanism of Action}

Vitamin D is a fat-soluble vitamin essential for life and known for its calcemic effects. Vitamin D refers to two compounds, vitamin $\mathrm{D}_{2}$ (ergocalciferol) and vitamin $\mathrm{D}_{3}$ (cholecalciferol). Vitamin D can be obtained from the diet or can be produced in the skin [9] (see Figure 1). It has been estimated that $80 \%$ of vitamin D supply comes from the production in the skin [10]. Endogenous vitamin $\mathrm{D}_{3}$ is produced in the skin from 7-dehydrocholesterol through a two-step process in which pre- $\mathrm{D}_{3}$ is first generated by UV light radiation from the sun, followed by a thermo-sensitive but non-catalytic step to form vitamin $\mathrm{D}_{3}$ [9]. Once vitamin $\mathrm{D}$ is produced in the skin or taken up from the diet, it enters the circulation and is bound to the vitamin $\mathrm{D}$ binding protein (DBP) for transport to the liver or other tissues in which it is hydroxylated by one or more 25-hydroxylases (CYP2R1, CYP27A1, CYP3A4) into 25 hydroxyvitamin $\mathrm{D}(25(\mathrm{OH}) \mathrm{D})$. The latter is the major circulating form of vitamin $\mathrm{D}$ and its plasma levels, because of its long half-life (15 days), are routinely measured as a marker of vitamin D status. The conversion to $25(\mathrm{OH}) \mathrm{D}$ is achieved primarily in the liver but can also occur in a variety of other tissues such as breast, colon, skin, ovary, lung, etc [11]. This form is, however, biologically inactive and must be converted in the kidney by $1 \alpha$-hydroxylase (CYP27B 1 ) to $1,25(\mathrm{OH})_{2} \mathrm{D}$ which is the active form of vitamin $\mathrm{D}$. The active form has a much shorter half-life (4 hours) and can therefore not be used to measure vitamin D status [12]. The activity of CYP27B1 is critical for the production and maintenance of physiologic levels of circulating $1,25(\mathrm{OH})_{2} \mathrm{D}$ and is therefore tightly regulated. Broad studies suggest that the expression of CYP27B1 may not be restricted to the kidney but it is synthesized in other cell types as well (lung, monocytes, macrophages) [13]. In the kidney, the degradation of $1,25(\mathrm{OH})_{2} \mathrm{D}$ is accomplished via the action of CYP24A1. Besides conversion to $1,25(\mathrm{OH})_{2} \mathrm{D}$ by CYP27B $1,25(\mathrm{OH})$ $\mathrm{D}$ can also be converted to $24,25(\mathrm{OH})_{2} \mathrm{D}$ by hydroxylation by CYP24A1in the kidney, leading to secretion into the 
blood. CYP24A1 is reciprocally regulated by $1,25(\mathrm{OH})_{2} \mathrm{D}$ itself and by parathyroid hormone (PTH) to sustain systemic levels of $1,25(\mathrm{OH})_{2} \mathrm{D}$ [14] (Figure 1).

The direct, well-controlled, and fast actions of vitamin D in the context of calcium homeostasis have been extensively described elsewhere [15]. 1,25(OH) $)_{2} \mathrm{D}$ also exerts genomic actions by regulating gene transcription true binding to a nuclear Vitamin D receptor (VDR) and forming a heterodimer with the retinoid $\mathrm{X}$ receptor (RXR), regulating in this way $3 \%$ of the human genome $[13,16,17]$. As such, vitamin $\mathrm{D}$ regulates genes that are linked to diverse biological processes such as cell proliferation and differentiation, cell control, apoptosis, and angiogenesis [18]. Vitamin D exerts diverse and extensive effects on the immune system, due to the expression of VDR, vitamin D metabolic enzymes, and the expression of the enzyme CYP27B1 by most immune cells, including macrophages, neutrophils, T cells, B cells, and dendritic cells $[19,20]$. Also airway epithelial cells as well as immune cells in the lung express VDR. Interestingly, the expression of CYP27B1 has been detected also in pulmonary immune cells resulting in local activation of $25(\mathrm{OH})$ $\mathrm{D}$ in the lung [21]. In contrast to renal $1 \alpha$-hydroxylation of $25(\mathrm{OH}) \mathrm{D}$, it has been suggested that CYP27B1 in the lung is not depending on a negative feedback control of $1,25(\mathrm{OH})_{2} \mathrm{D}$ itself [22] which might result in higher local levels of the active compound. It may indicate therefore that vitamin D can be used as an agent with immune regulatory actions in the lung and therefore be used to prevent or treat respiratory infections.

\section{Vitamin D to Prevent or Treat Exacerbations}

Vitamin D deficiency is highly prevalent in common respiratory diseases such as cystic fibrosis (CF), chronic obstructive pulmonary disease (COPD), and asthma [23, 24]. A serum level of $25(\mathrm{OH}) \mathrm{D}<25 \mathrm{nmol} / \mathrm{l}$ has been a traditional cutoff used for several decades to define vitamin $\mathrm{D}$ deficiency [25]. In most studies, vitamin D deficiency is defined as serum 25(OH)D levels $<20 \mathrm{ng} / \mathrm{ml}$, insufficiency as $25(\mathrm{OH})$ $\mathrm{D}<30 \mathrm{ng} / \mathrm{ml}$, and sufficiency as $25(\mathrm{OH}) \mathrm{D}>30 \mathrm{ng} / \mathrm{ml}$. Based on these criteria, vitamin D deficiency is widespread across Europe [26] and the world [27] at prevalence rates that reach the criteria of a pandemic. Vitamin D status is largely determined by the level of skin synthesis and dietary intake. Vitamin D synthesized in the skin is dependent on UVB exposure and therefore influenced by latitude, skin pigmentation, skin coverage, time spent outdoors, and use of sunscreen. Dietary vitamin D can be obtained through naturally occurring vitamin $\mathrm{D}_{2}$ or $\mathrm{D}_{3}$ in food, dietary supplementation, or food fortification. A number of other factors such as adiposity, genetics, age, sex, and specific diseases also contribute to variation [28]. Traditional risk groups to develop vitamin D deficiency include newborns, pregnant women, older persons, and people in diseased states [27, 29]. Vitamin D deficiency was shown to be very prevalent in populations with chronic lung diseases. Fifty-nine per cent of patients with diffuse parenchymal lung diseases undergoing evaluation for lung transplant were found to have decreased vitamin D levels [30].

The respiratory tract is constantly exposed to the external environment and must therefore be well equipped to respond to and eliminate pathogens. The activation of pathogen recognition receptors (PRRs) on the respiratory epithelial cells is critical to limit viral or bacterial spread and to activate the immune system. Generally, PRR signaling upregulates cellautonomous and non-cell-autonomous immune responses to infection. Cell-autonomous functions include the secretion of anti-microbial peptides by epithelial cells, programmed cell death, and other intracellular response pathways. Noncell-autonomous processes are more linked to the initiation of the immune system by releasing pro-inflammatory mediators, cytokines, and chemokines [31, 32]. Vitamin $\mathrm{D}$ can interfere with several of these steps involved in the elimination of viruses and bacteria and in the activation of the immune system (Figure 2). First, vitamin D is involved in the regulation of the PRRs which are believed to play a crucial role in the proper function of the innate immune system. PRRs are expressed by dendritic cells, macrophages, monocytes, neutrophils, and epithelial cells. After stimulation of PRRs, a cascade of reactions is initiated that directs host defense responses such as production of cytokines and anti-microbial peptides (AMPs) [33]. Vitamin D enhances the production of AMPs such as cathelicidin and $\beta$-defensin $[34,35]$, which serve as a first line of defense against invading pathogens. Secondly, stimulation of PRRs also leads to induction of antigen-presenting cells to initiate the adaptive immune system. Vitamin D also modulates the adaptive immune system first by attenuating the antigen-presenting capacity of Antigen-presenting cells, such as dendritic cells and macrophages [7]. Furthermore, vitamin D was shown to enhance the phagocytic and chemotactic capacity of macrophages $[19,36]$ and it acts to suppress $\mathrm{T}$ celldriven inflammation and enhance the effects of Tregs by increased production of anti-inflammatory cytokines (Il-10, Il-4, TGF $\beta$ ) [37]. Also B cells are affected by vitamin D, as shown by decreased immunoglobulin production, proliferation, and differentiation but increased apoptosis [7].

The importance of vitamin D deficiency in respiratory infections was emphasized in observational studies that consistently reported independent associations between low serum concentrations of $25(\mathrm{OH}) \mathrm{D}$ and susceptibility to acute respiratory infection [38]. Upper respiratory tract infections (URI), mostly caused by a rhinoviral infection, are believed to be one of the major causes of exacerbations. Serum levels of $25(\mathrm{OH}) \mathrm{D}$ were shown to be inversely correlated with 


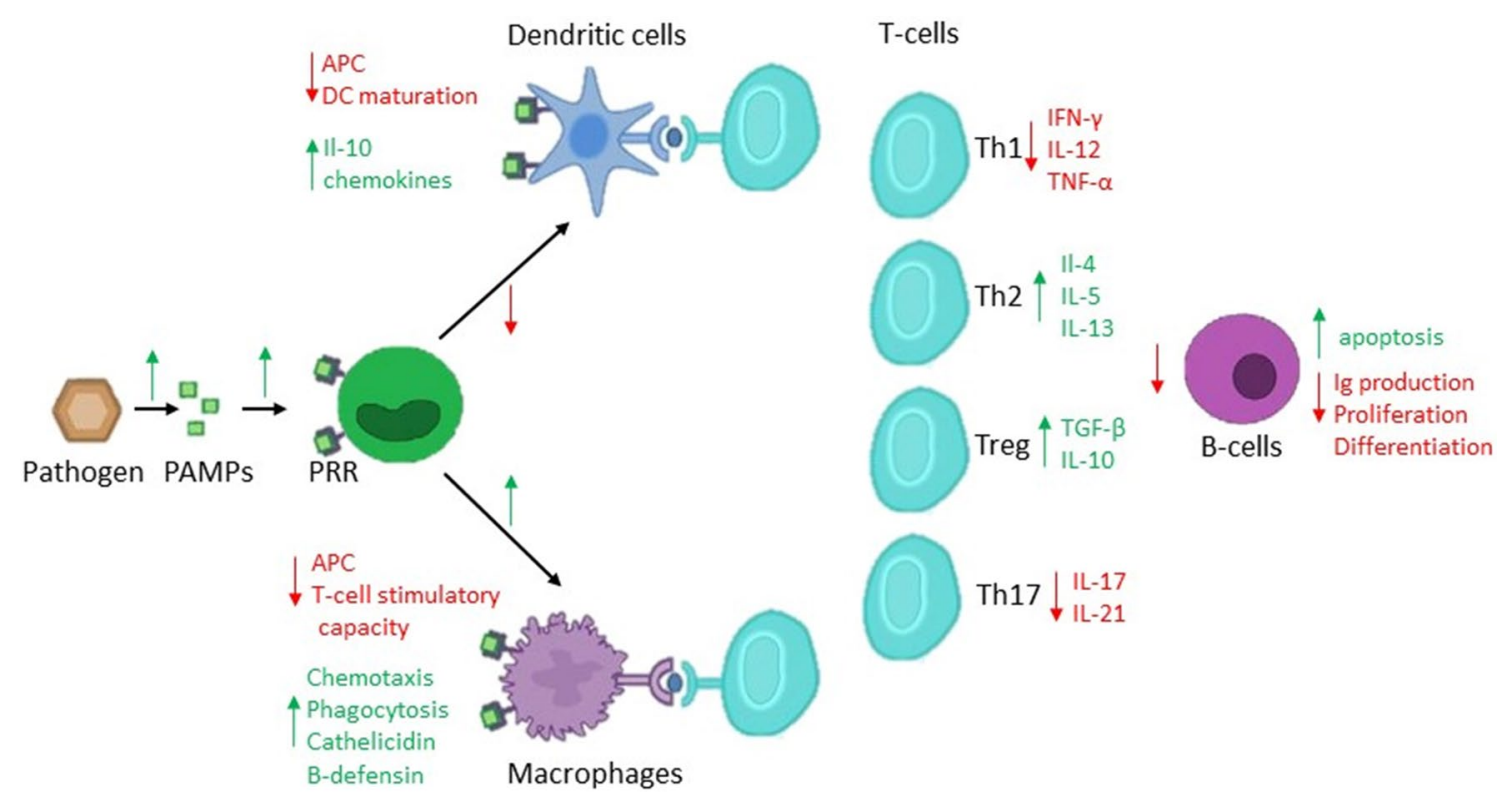

Fig. 2 Immunomodulatory actions of $1,25(\mathrm{OH})_{2} \mathrm{D}$. Arrow down in red: inhibiting effects of vitamin $\mathrm{D}$, arrow up in green: activating effects of vitamin D. PAMPs: pathogen-associated molecular pat-

upper respiratory tract infections [39]. Also genetic studies confirm that polymorphism in the VDR independently associates with susceptibility to URI. Finally, in vitro studies in epithelial cell lines [40] and in human primary bronchial epithelial cells $[41,42]$ infected with rhinoviruses show that vitamin $\mathrm{D}$ is able to increase the antiviral defenses most likely via an upregulation of cathelicidin. From a mechanistic point of view, it is clear that vitamin D can be an important modulator of the host defense against respiratory infections by potentiating the clearance of pathogens while attenuating the associated inflammatory burst. As such it is important to explore vitamin D's role in the prevention or treatment of exacerbations in respiratory diseases. Detailed data on CF, COPD, and asthma will be discussed in the next paragraphs.

\section{Vitamin D in Cystic Fibrosis}

Cystic fibrosis (CF) is a common autosomal recessive disorder where a mutation in the CFTR gene results in a dysregulation of ion transport across epithelial surfaces leading to abnormally thickened mucus on the surface of the lungs. Because of the defective mucociliary clearance, bacteria cannot be eradicated and survive and proliferate leading to chronic bronchial infections. Acute pulmonary exacerbations are a very common event in CF patients and are usually triggered by respiratory viruses or bacteria. These repeated infections might lead to chronic infections and inflammation of the airways leading to progressive destruction of the terns, PRR: pathogen recognition receptor (adapted from Greiller et al [7] under the terms of the CC Attributions 4.0 International (CC BY 4.0) license)

lungs and respiratory failure [43]. Pulmonary exacerbations in CF have a profound impact on the morbidity and quality of life of individuals with CF [44]. Therefore efforts should be made to improve the management of these events.

Patients with CF often experience nutritional deficits, including vitamin D due to poor nutritional uptake, secondary fat malabsorption, decreased sunlight exposure, and impairment in hepatic hydroxylation of vitamin D $[45,46]$. Vitamin D deficiency is common in patients with CF and prevalence ranges from 40 to $90 \%$, depending on age and definition of deficiency $[45,47]$. Treatment guidelines for vitamin $\mathrm{D}$ in the CF population only focus on optimizing bone health [48] and despite nutritional management recommendations, vitamin D deficiency can still be present even after supplementation [48, 49]. Associations between vitamin D status, lung function, and exacerbations are unclear. Indeed, some studies found positive associations with levels of vitamin D and lung function, as measured by FEV1 [47, 49-54] while others found no relationship [55-58]. When we focus on the relationship between serum $25(\mathrm{OH}) \mathrm{D}$ levels and exacerbations in $\mathrm{CF}$, most studies reported that deficient vitamin D levels $(25(\mathrm{OH}) \mathrm{D}<20 \mathrm{ng} / \mathrm{ml})$ are associated with more exacerbations $[47,49,50]$ and more bacterial colonizations [59]. Only one large multicenter intervention study in $\mathrm{CF}$ has been performed trying to prevent exacerbations in CF [60]. In this study, 25,000 IU of vitamin $\mathrm{D}_{3}$ were given to adults with $\mathrm{CF}$ at the time of a pulmonary exacerbations, resulting in significant increases in serum $25(\mathrm{OH}) \mathrm{D}$ concentrations remaining for the complete 
duration of the study. No improvement of the time to next exacerbation or the 1-year survival was observed and there were no differences in lung function recovery or concentration of plasma cathelicidin [60]. These results are in contrast with the pilot study performed by the same group showing that bolus vitamin D supplementation (25,000 IU), improved and maintained vitamin D status and improved clinical outcomes [61].

In vitro mechanistic studies in cell lines have shown that vitamin $\mathrm{D}$ can be converted to its active form when topically administered to airway cells [62] while in a bronchial epithelial cell line with a CFTR mutation this ability was lost [63]. Although this loss was only observed in one particular cell line, it may suggest that the ability to convert vitamin $\mathrm{D}$ to its active form might be less available in CF airways. Other studies in CF respiratory cell lines showed anti-inflammatory and anti-bacterial effects after treatment with $1,25(\mathrm{OH})_{2} \mathrm{D}$ in response to bacterial stimuli $[64,65]$. Furthermore, it was demonstrated that vitamin D increased the mRNA expression of cathelicidin from primary bronchial epithelial cells collected from $\mathrm{CF}$ patients with no evidence for an antiviral response following a rhinoviral infection [42]. Even though mechanistic studies mostly were done in vitro, few studies in human suggest that the positive effects of vitamin D on exacerbations in CF are mostly attributed to its immunomodulatory properties as reflected by reduced serum IL-6, TNF levels [61], and IL-8 levels [66] or reduced serum $\operatorname{Ig}(G)$ levels [45]. A study on metabolomics on plasma of a supplemented CF population revealed that the beneficial effects of high-dose vitamin D in hospitalized CF adults with an acute pulmonary exacerbation may have occurred through a metabolic stabilization of amino acids, lipids, and other metabolites [67].

Based on one RCT with vitamin D supplementation in $\mathrm{CF}$ and the conflicting results in observational trials, it is difficult to conclude whether vitamin $\mathrm{D}$ can be used as an adjunctive therapy for CF exacerbations. Future investigations are needed to conclude if low-cost supplementation with vitamin $\mathrm{D}$ can be beneficial in preventing or treating exacerbations in the CF population. A difficult issue to address in any study in a CF population is the presence of many cofounders in this complex disease. Patients are diagnosed with the disease already at very young ages and it is known that the prevalence of vitamin D deficiency increases with age [47]. Some CF patients have poorer compliance to their medications, including vitamin D supplements and sicker patients may spend less time outdoors and may have less sun exposure or less appetite and therefore eat fewer vitamin D containing foods. These factors all contribute to the fact that studies that have addressed the relationship between vitamin D status and pulmonary function or exacerbations in CF show conflicting results.

\section{Vitamin D in COPD and Exacerbations}

COPD is characterized by airflow limitation that is not fully reversible and is associated with an abnormal inflammatory response in the lungs to noxious particles or gases [68]. Smoking is the most important risk factor to develop COPD and accounts for $95 \%$ of COPD cases. COPD is complicated by exacerbations that are mostly triggered by respiratory viruses or bacteria. Studies have indicated that the quality of life and health status of patients are mainly determined by the presence and frequency of exacerbations [4]. Indeed, COPD exacerbations have important clinical and economic consequences, including lost work productivity, increased utilization of healthcare resources, temporary or permanent reductions in lung function and exercise capacity, hospitalization, and sometimes death [69]. Although the precise mechanisms of the onset of COPD exacerbations have not been fully clarified, the viral/bacterial infection-mediated immune response is thought to play a critical role.

Vitamin D deficiency (defined as serum 25 hydroxyvitamin $\mathrm{D}<20 \mathrm{ng} / \mathrm{ml}$ ) has been shown to be highly prevalent in COPD patients compared to age-matched healthy controls and increased with disease severity [24]. COPD patients are at risk for vitamin $\mathrm{D}$ deficiency for a variety of reasons, including unbalanced diet, absence of outdoor activity, and therefore, sun exposure and reduced capacity for vitamin D synthesis due to premature aging of the skin and smoking, increased vitamin D catabolism by glucocorticoids and lower vitamin D storage capacity [70]. Additionally, the majority of COPD patients are elderly, known to be more vitamin $\mathrm{D}$ deficient than the younger population. Clear associations have been found between vitamin D status and COPD. Indeed, meta-analysis reported inverse associations between vitamin D levels and COPD risk and COPD severity (Zhu 2016). Also epidemiologic studies reported a strong relationship between vitamin D levels and pulmonary function (FEV1 and FVC) [70-72]. In animal studies, vitamin $\mathrm{D}$ deficiency was shown to promote an early lung function decline after cigarette smoke [66], suggesting a role for vitamin D in the development of COPD. The association between vitamin D serum levels and the frequency of exacerbations is, however, still unclear [73]. In the meta-analysis of Zhu et al [74], no clear relationship was reported. In fact, two studies showed that vitamin D deficiency was related to more frequent exacerbations $[75,76]$, while other studies did not show such association [77-81]. Interestingly, polymorphisms in the vitamin $\mathrm{D}$ binding protein gene might also be related 
to higher exacerbation frequencies (Ishii 2014), suggesting a relationship between vitamin D and the occurrence of exacerbations. Current strategy to treat exacerbations in COPD includes long-acting bronchodilators and longterm use of inhaled corticosteroids or macrolide antibiotics but they are all modestly effective and evidence on the preferred drug and optimal treatment duration are lacking [82]. An attractive alternative target for intervention studies in COPD is the vitamin D pathway.

Few RCTs with vitamin D supplementation aimed to prevent COPD exacerbations have been performed. A supplementation of 100,000 IU monthly for 1 year, resulting in sufficient serum vitamin D levels, showed no effect of vitamin $\mathrm{D}$ supplementation on the number of exacerbations. However, in a subgroup analysis of patients with severe vitamin D deficiency at baseline $(25(\mathrm{OH}) \mathrm{D}$ levels $<10 \mathrm{ng} / \mathrm{ml}$ ), a significant reduction in exacerbations was observed [83]. Similar results were observed by two other studies $[84,85]$ and by a recent meta-analysis, including all individual patient data, confirming that the protective effect of vitamin D supplementation against COPD exacerbations is restricted to those with the lowest baseline 25(OH)D levels [86]. Two large RCTs are still ongoing and might give us more insight into the role of vitamin D in exacerbations: Lung VITAL [87] and PRECOVID [88]. The ongoing Lung VITAL study is taking advantage of a large clinical trial: VITAL, to conduct the first major evaluation of the influences of vitamin D supplementation on respiratory exacerbation in a sub-cohort enriched for active, symptomatic respiratory disease, over a period of 5 years. The PRECOVID study will be the first RCT examining the effects of vitamin D supplementation on exacerbation rate in vitamin D-deficient COPD patients. As shown in the meta-analysis of prior studies [86], the anticipated effect in this targeted subgroup may be huge.

Insights in the mechanisms of vitamin $\mathrm{D}$ to treat or prevent COPD exacerbations come from several mechanistic studies in vitro. In alveolar macrophages of smokers and non-smokers, it was shown that $1,25(\mathrm{OH})_{2} \mathrm{D}$ inhibited the release of pro-inflammatory cytokines such as TNF $\alpha$, MCP-1, and IL-6 in response to LPS/IFN- $\gamma$ stimulation [36]. This was confirmed in a macrophage cell line exposed to cigarette smoke extract [36] or to LPS [89, 90]. $1,25(\mathrm{OH})_{2} \mathrm{D}$ did not show any effect on the phagocytic capacity of these macrophages but it increased the levels of cathelicidin [36]. Furthermore, in venous blood samples, the rate of peripheral blood neutrophilic apoptosis in patients with acute exacerbations of COPD was slower than in healthy controls and this neutrophilic apoptosis is increased after administration of vitamin D through the p38MAPK pathway [91]. Taken together, even though in a controlled setting of cell culture, these data clearly show that vitamin D has potential to interfere with the immune reaction in response to a respiratory infection in COPD.

\section{Vitamin D in Asthma Exacerbation}

Asthma is a chronic inflammatory disease of the airway, which is characterized by airway inflammation, airway hyper responsiveness (AHR), mucus hypersecretion, and airway remodeling. The latter is irreversible and includes airway wall thickening, increased airway muscle mass, and subepithelial fibrosis, which restricts the constant airflow. Respiratory tract infections are common precipitants of acute asthma exacerbations in adults, playing a role in about $45-80 \%$ of exacerbations. Asthma mortality arises primarily during episodes of exacerbations, mostly due to viral respiratory infections, but also to exposure to particulate matter [92].

Many studies have reported high prevalence of vitamin D deficiency in asthmatic children, ranging from $50-80 \%$ worldwide $[93,94]$. This was confirmed in a systematic review showing that children with asthma have lower vitamin D levels than healthy age-matched children [95]. Inadequate dietary intake, low use of vitamin D supplements, skin pigmentation, obesity, and low sun exposure all increase the risk of vitamin D insufficiency. Whether vitamin $\mathrm{D}$ intake during pregnancy has an impact on the development of childhood asthma is unclear as one metaanalysis found no significant association between prenatal vitamin D status and risk of asthma. However, recently, it was suggested that lower maternal vitamin $\mathrm{D}$ intake during pregnancy is associated with increased risk of children wheezing and being diagnosed with asthma in the first 10 years [96], indicating a role for vitamin D in the development of childhood asthma.

Vitamin D deficiency has been linked to an overall poor outcome of lung function and symptoms in patients with asthma [97-100]. Additionally, it was shown that the response to standard corticosteroid therapy was reduced in vitamin D-deficient asthmatic patients [101]. Studies in asthma also suggest an association between vitamin D deficiency and exacerbations [102, 103]. More specifically, vitamin D deficiency is associated with an increased risk for exacerbations [104]. In a 4-year follow-up study, Brehm found that vitamin D insufficiency $(25(\mathrm{OH})$ $\mathrm{D}<30 \mathrm{ng} / \mathrm{ml}$ ) at baseline was associated with increased risk of severe asthma exacerbations [105]. The magnitude of this association was the greatest in children who were vitamin D insufficient and did not receive corticosteroids [94]. By contrast, Boonpiyatad et al observed that vitamin D deficiency indeed was present in patients with asthma exacerbations but could not find a causal relationship [106]. Additionally, it was shown that children who were 
both vitamin $\mathrm{D}$ deficient and living near a major roadway were 5 times more likely to experience asthma exacerbations in comparison with children who were vitamin D sufficient and living in the same regions of high particulate matter [107]. This indicates that vitamin D deficiency represents an important factor in the development of exacerbations during asthma.

Current treatment of asthma exacerbations consists in a stepwise approach with increasing doses of medications, primarily inhaled corticosteroids (ICS), often in conjunction with a second controller medication to achieve disease control [108]. For most asthma patients, particularly those with mild-to-moderate disease, guideline-directed step care is effective resulting in symptom control and prevention of exacerbations. In severe asthma, however, this stepwise approach is not effective resulting in diminished responsiveness to treatment and need for alternative treatment strategies. As such, supplementation with vitamin D to treat vitamin $\mathrm{D}$ insufficiency might be an alternative strategy to prevent frequent exacerbations in asthmatic patients.

Indeed, many RCTs of vitamin D supplementation to improve asthma control and exacerbations have been completed and these studies have reported a mixture of positive and negative results. However, several meta-analyses show that vitamin D supplementation significantly reduced the rate of severe exacerbations in patients with asthma [109-113]. Whether these effects are only observed in patients with vitamin D deficiency, as was shown in COPD, is less clear since only two studies performed subgroups analysis, showing conflicting results [112, 113]. While the most recent meta-analysis clearly concluded that vitamin D supplementation played a role in reducing the rate of exacerbations particularly in patients with vitamin D insufficiency [113], subgroup analysis using individual patient data did not result in such a firm conclusion [112]. Indeed, reductions in exacerbation rate were found with vitamin D supplementations but only in participants with baseline circulating 25(OH)D levels less than $25 \mathrm{nmol} / \mathrm{l}$ and not in those with higher levels of circulating $25(\mathrm{OH}) \mathrm{D}$ (adjusted incidence rate ratio was 0.33 (95\% CI 0.11-0.98) and 0.77 (95\% CI 0.58-1.03), respectively). However, the p value for interaction for this subgroup analysis was not significant indicating no definitive evidence that effects of the intervention with vitamin $\mathrm{D}$ differed across subgroups of patients [112]. Interestingly, most intervention studies are performed in adults, while many children are suffering from asthma as well. Recent studies report that vitamin D supplementation helps in preventing the development of asthma and recurrent wheeze in early life, and may also help in the management of asthma during childhood [114, 115].

Mechanistic studies in peripheral blood mononuclear cells (PBMCs) isolated from patients with severe asthma reported an inhibition of the production of Th17 cytokines (IL-17 and IL-22), important in the pathogenesis of asthma, after treatment with $1,25(\mathrm{OH})_{2} \mathrm{D}$ [116]. These Th17 cytokines were not inhibited by corticosteroids suggesting a steroid-enhancing property of vitamin D in asthmatic patients. In PBMCs from patients with severe asthma exacerbation and vitamin D deficiency, increased oxidative stress and DNA damage were observed compared to vitamin D-sufficient asthmatic patients with an exacerbation. In the same study, vitamin D was shown to down-regulate the expression of TNF- $\alpha, \mathrm{NF \kappa B}$, and its phosphorylation in an LPS-stimulated airway epithelial cell line suggesting a possible mechanism for vitamin D therapy in severe asthma exacerbation [117]. Additionally, when asthma patients were treated with vitamin $\mathrm{D}$, a reduction of respiratory infections was observed, and this effect was related to the increase in cathelicidin [118].

As in COPD and in CF, we should be careful in drawing conclusions concerning the role of vitamin $\mathrm{D}$ in asthma exacerbations. Most intervention studies are performed in adults and these results cannot be generalized to children. Still little is known about the optimal serum 25(OH)D levels to exert beneficial effects on the respiratory system. Additionally, it was observed that a rapid vitamin D supplementation (intramuscularly) compared to maintenance dose of vitamin D supplementation (orally) for children with low levels of vitamin D resulted in short- but not long-term reduction in asthma exacerbations [119].

\section{Considerations and Future Perspectives}

The relationship between Vitamin D and the respiratory system remains inconclusive. Even though most exacerbations are triggered by a respiratory infection, different pathways or mechanisms are activated with respect to the respiratory disease. Larger clinical trials and more comparable data are needed to draw conclusions on vitamin D's association with the risk of exacerbations. It is possible that failure to demonstrate an association between vitamin D deficiency and increased exacerbation risk in some studies or populations may be related to the low prevalence of participants with low baseline vitamin D levels. Indeed, mainly in COPD exacerbations, it was shown that actually only the severely deficient patients benefit from vitamin D supplementation. Moreover, even though the relationship between low serum levels of vitamin $\mathrm{D}$ and exacerbations remains disputable, vitamin $\mathrm{D}$ supplementation may still exert anti-infectious effects. Irrespective of the reasons for the discrepancy between different studies, some important issues should be taken into account when developing new clinical studies.

Currently, it is not known if aiming at sufficient serum levels of vitamin $\mathrm{D}$ is a good approach to benefit from the anti-inflammatory and anti-bacterial actions of vitamin D. 
And if so, which serum levels can be considered as "beneficial"? Can we assume that these levels should be similar in all populations and in all respiratory diseases? Additionally, can we assume that all populations, healthy and patients, need similar oral doses to reach certain serum levels? For example, CF patients seem to require much higher doses to achieve similar vitamin $\mathrm{D}$ serum levels than patients with other respiratory diseases. Are circulating levels of $25(\mathrm{OH})$ $\mathrm{D}$ the best way to measure vitamin D status? 25(OH)D levels represent the reservoir available for the production of active $1,25(\mathrm{OH})_{2} \mathrm{D}$ produced in the kidney by an enzymatic conversion. It is unclear how these serum levels relate to local tissue concentrations. Therefore, there are several pathways that can influence an individual's ability to produce an adequate amount of locally active vitamin $\mathrm{D}$ irrespective of its serum levels.

Little is known about the total dose and dose interval needed for the extra-skeletal effects of vitamin D. We speculate that the current dosing regimens and levels in interventional trials might be insufficient to fully benefit the potential actions of vitamin D. Interestingly, individual patient data analysis even revealed that daily or weekly dosing of vitamin $\mathrm{D}$ without additional bolus doses protected against acute respiratory infection, whereas regimens containing large boluses did not suggest that daily or weekly vitamin D administration would be a better strategy to protect against URI. This might be due to the potential adverse effects of fluctuations in circulating $25(\mathrm{OH}) \mathrm{D}$ concentrations, which are observed after bolus dosing [120]. In recent years, interest in the tolerance-inducing potential of vitamin D to modulate immune cells has grown, but one of the major obstacles for the use of active vitamin D is the need for supra-physiological doses to modulate immune responses, risking side effects such as hypercalcemia, hypercalciuria, and kidney stones. In order to avoid adverse side effects of high serum levels of vitamin D, much effort has been made to develop vitamin D analogs that still exert the beneficial effects of vitamin D without the hypercalcemic side effects. Despite the efforts made to develop different analogs, not many, however, progressed beyond the preclinical stage [121]. Alternatively, to avoid side effects of vitamin D supplementation and to maximize the desired effectiveness, treatment locally into the lung as alternative routes of administration of vitamin D rather than peroral must be considered. Development of a drug for inhaled administration is often a common strategy to achieve high efficiency locally in the lungs and reduce side effects. However, in the case of vitamin D, the challenge is to find a vehicle that allows effective delivery of the lipophilic agent via inhalation with improved bioavailability and sustained release of vitamin D.

In conclusion, it is important to diagnose, prevent, and treat vitamin D deficiency, since it is an epidemic all over the world, not only in patients with respiratory diseases.
Vitamin D supplementation is a simple low-cost treatment that may help minimizing exacerbations in view of its immunomodulatory and anti-bacterial properties. However, efforts should be made to develop adequate strategies with vitamin $\mathrm{D}$ adapted for lung exacerbations rather than using existing treatment modalities with vitamin D supplementation.

\section{Compliance with Ethical Standards}

Conflict of interest Karen Maes, Jef Serré, Carolien Mathyssen, Wim Janssens and Ghislaine Gayan-Ramirez declare that they have no conflict of interest.

Open Access This article is distributed under the terms of the Creative Commons Attribution 4.0 International License (http://creativeco mmons.org/licenses/by/4.0/), which permits unrestricted use, distribution, and reproduction in any medium, provided you give appropriate credit to the original author(s) and the source, provide a link to the Creative Commons license, and indicate if changes were made.

\section{References}

1. Jolliffe DA, Griffiths CJ, Martineau AR (2013) Vitamin D in the prevention of acute respiratory infection: systematic review of clinical studies. J Steroid Biochem Mol Biol 136:321-329. https ://doi.org/10.1016/j.jsbmb.2012.11.017

2. Bilton D, Canny G, Conway S et al (2011) Pulmonary exacerbation: towards a definition for use in clinical trials. Report from the EuroCareCF working group on outcome parameters in clinical trials. J Cyst Fibros 10:S79-S81

3. Skolnik K, Quon BS (2018) Recent advances in the understanding and management of cystic fibrosis pulmonary exacerbations. F1000Research. https://doi.org/10.12688/f1000research.13926.1

4. Wedzicha JA, Singh R, Mackay AJ (2014) Acute COPD exacerbations. Clin Chest Med 35:157-163. https://doi.org/10.1016/j. ccm.2013.11.001

5. Fuhlbrigge A, Peden D, Apter AJ et al (2012) Asthma outcomes: exacerbations. J Allergy Clin Immunol 129:S34-S48. https://doi. org/10.1016/j.jaci.2011.12.983

6. Murray LA, Grainge C, Wark PA, Knight DA (2017) Use of biologics to treat acute exacerbations and manage disease in asthma, COPD and IPF. Pharmacol Ther 169:1-12. https://doi. org/10.1016/j.pharmthera.2016.11.003

7. Greiller CL, Martineau AR (2015) Modulation of the immune response to respiratory viruses by vitamin D. Nutrients 7:4240 4270. https://doi.org/10.3390/nu7064240

8. Bosch AATM, Biesbroek G, Trzcinski K et al (2013) Viral and bacterial interactions in the upper respiratory tract. PLoS Pathog 9(1): 1003057

9. Bikle DD (2014) Vitamin D metabolism, mechanism of action, and clinical applications. Chem Biol 21:319-329. https://doi. org/10.1016/j.chembiol.2013.12.016

10. Pilz S, Zittermann A, Trummer C et al (2019) Vitamin D testing and treatment: a narrative review of current evidence. Endocr Connect 8:R27-R43. https://doi.org/10.1530/EC-18-0432

11. Hollis BW, Wagner CL (2013) Clinical review: the role of the parent compound vitamin D with respect to metabolism and function: why clinical dose intervals can affect clinical outcomes. 
J Clin Endocrinol Metab 98:4619-4628. https://doi.org/10.1210/ jc.2013-2653

12. Holick MF, Binkley NC, Bischoff-Ferrari HA et al (2011) Evaluation, treatment, and prevention of vitamin D deficiency: an Endocrine Society clinical practice guideline. J Clin Endocrinol Metab 96:1911-1930. https://doi.org/10.1210/jc.2011-0385

13. Pike JW, Christakos S (2017) Biology and mechanisms of action of the vitamin D hormone. Endocrinol Metab Clin North Am 46:815-843. https://doi.org/10.1016/j.ecl.2017.07.001

14. Christakos S, Dhawan P, Verstuyf A et al (2016) Vitamin D: metabolism, molecular mechanism of action, and pleiotropic effects. Physiol Rev 96:365-408. https://doi.org/10.1152/physr ev.00014.2015

15. Goltzman D, Mannstadt M, Marcocci C (2018) Physiology of the calcium-parathyroid hormone-vitamin D axis. Front Horm Res 50:1-13. https://doi.org/10.1159/000486060

16. Holick MF (2007) Vitamin D deficiency. N Engl J Med 357:266281. https://doi.org/10.1056/NEJMra070553

17. Kutner A, Brown G (2018) Vitamins D: relationship between structure and biological activity. Int J Mol Sci 19(7):2119

18. Caprio M, Infante M, Calanchini M et al (2017) Vitamin D: not just the bone. Evidence for beneficial pleiotropic extraskeletal effects. Eat Weight Disord EWD 22:27-41. https://doi. org/10.1007/s40519-016-0312-6

19. Baeke F, Takiishi T, Korf $\mathrm{H}$ et al (2010) Vitamin D: modulator of the immune system. Curr Opin Pharmacol 10:482-496. https ://doi.org/10.1016/j.coph.2010.04.001

20. Hewison M (2012) Vitamin D and immune function: an overview. Proc Nutr Soc 71:50-61. https://doi.org/10.1017/S0029 665111001650

21. Hansdottir S, Monick MM, Hinde SL et al (2008) Respiratory epithelial cells convert inactive vitamin D to its active form: potential effects on host defense. J Immunol Baltim Md 181:7090-7099

22. Overbergh L, Decallonne B, Valckx D et al (2000) Identification and immune regulation of 25-hydroxyvitamin D-1-alpha-hydroxylase in murine macrophages. Clin Exp Immunol 120:139-146

23. Hejazi ME, Modarresi-Ghazani F, Entezari-Maleki T (2016) A review of Vitamin D effects on common respiratory diseases: asthma, chronic obstructive pulmonary disease, and tuberculosis. J Res Pharm Pract 5:7-15. https://doi.org/10.4103/2279042X.176542

24. Janssens W, Bouillon R, Claes B et al (2010) Vitamin D deficiency is highly prevalent in COPD and correlates with variants in the vitamin D-binding gene. Thorax 65:215-220. https://doi. org/10.1136/thx.2009.120659

25. Institute of Medicine (US) Committee to Review Dietary Reference Intakes for Vitamin D and Calcium (2011) Dietary reference intakes for calcium and vitamin D. National Academies Press, Washington DC

26. Cashman KD (2015) Vitamin D: dietary requirements and food fortification as a means of helping achieve adequate vitamin D status. J Steroid Biochem Mol Biol 148:19-26. https://doi. org/10.1016/j.jsbmb.2015.01.023

27. Palacios C, Gonzalez L (2014) Is vitamin D deficiency a major global public health problem? J Steroid Biochem Mol Biol 144:138-145

28. Fuleihan GE-H, Bouillon R, Clarke B et al (2015) Serum 25-hydroxyvitamin D levels: variability, knowledge gaps, and the concept of a desirable range. J Bone Miner Res 30:1119-1133. https://doi.org/10.1002/jbmr.2536

29. van Schoor NM, Lips P (2011) Worldwide vitamin D status. Best Pract Res Clin Endocrinol Metab 25:671-680. https://doi. org/10.1016/j.beem.2011.06.007

30. Førli L, Halse J, Haug E et al (2004) Vitamin D deficiency, bone mineral density and weight in patients with advanced pulmonary disease. J Intern Med 256:56-62. https://doi.org/10. 1111/j.1365-2796.2004.01337.x

31. Newton AH, Cardani A, Braciale TJ (2016) The host immune response in respiratory virus infection: balancing virus clearance and immunopathology. Semin Immunopathol 38:471-482. https ://doi.org/10.1007/s00281-016-0558-0

32. Crane MJ, Xu Y, Henry WL et al (2018) Pulmonary influenza A virus infection leads to suppression of the innate immune response to dermal injury. PLoS Pathog 14:e1007212. https:// doi.org/10.1371/journal.ppat.1007212

33. Hansdottir S, Monick MM (2011) Vitamin D effects on lung immunity and respiratory diseases. Vitam Horm 86:217-237. https://doi.org/10.1016/B978-0-12-386960-9.00009-5

34. Korf H, Decallonne B, Mathieu C (2014) Vitamin D for infections. Curr Opin Endocrinol Diabetes Obes 21:431-436. https:// doi.org/10.1097/MED.0000000000000108

35. Tjabringa GS, Rabe KF, Hiemstra PS (2005) The human cathelicidin LL-37: a multifunctional peptide involved in infection and inflammation in the lung. Pulm Pharmacol Ther 18:321-327. https://doi.org/10.1016/j.pupt.2005.01.001

36. Heulens N, Korf H, Mathyssen C et al (2016) 1,25-dihydroxyvitamin $\mathrm{D}$ modulates antibacterial and inflammatory response in human cigarette smoke-exposed macrophages. PLoS ONE 11:e0160482. https://doi.org/10.1371/journal.pone.0160482

37. Bouillon R, Marcocci C, Carmeliet G et al (2018) Skeletal and extra-skeletal actions of vitamin D: current evidence and outstanding questions. Endocr Rev 40(4):1109-1151

38. Martineau AR, Jolliffe DA, Greenberg L et al (2019) Vitamin D supplementation to prevent acute respiratory infections: individual participant data meta-analysis. Health Technol Assess Winch Engl 23:1-44. https://doi.org/10.3310/hta23020

39. Ginde AA, Mansbach JM, Camargo CA (2009) Association between serum 25-hydroxyvitamin D level and upper respiratory tract infection in the Third National Health and Nutrition Examination Survey. Arch Intern Med 169:384-390. https://doi. org/10.1001/archinternmed.2008.560

40. Greiller CL, Suri R, Jolliffe DA et al (2019) Vitamin D attenuates rhinovirus-induced expression of intercellular adhesion molecule-1 (ICAM-1) and platelet-activating factor receptor (PAFR) in respiratory epithelial cells. J Steroid Biochem Mol Biol 187:152-159. https://doi.org/10.1016/j.jsbmb.2018.11.013

41. Telcian AG, Zdrenghea MT, Edwards MR et al (2017) Vitamin D increases the antiviral activity of bronchial epithelial cells in vitro. Antiviral Res 137:93-101. https://doi.org/10.1016/j. antiviral.2016.11.004

42. Schögler A, Muster RJ, Kieninger E et al (2016) Vitamin $\mathrm{D}$ represses rhinovirus replication in cystic fibrosis cells by inducing LL-37. Eur Respir J 47:520-530. https://doi. org/10.1183/13993003.00665-2015

43. Elborn JS (2016) Cystic fibrosis. Lancet Lond Engl 388:25192531. https://doi.org/10.1016/S0140-6736(16)00576-6

44. Goss CH, Burns JL (2007) Exacerbations in cystic fibrosis. 1: epidemiology and pathogenesis. Thorax 62:360-367. https://doi. org/10.1136/thx.2006.060889

45. Chesdachai S, Tangpricha V (2016) Treatment of vitamin D deficiency in cystic fibrosis. J Steroid Biochem Mol Biol 164:36-39. https://doi.org/10.1016/j.jsbmb.2015.09.013

46. Tangpricha V, Kelly A, Stephenson A et al (2012) An update on the screening, diagnosis, management, and treatment of vitamin $\mathrm{D}$ deficiency in individuals with cystic fibrosis: evidencebased recommendations from the cystic fibrosis Foundation. J Clin Endocrinol Metab 97:1082-1093. https://doi.org/10.1210/ jc. 2011-3050

47. McCauley LA, Thomas W, Laguna TA et al (2014) Vitamin $\mathrm{D}$ deficiency is associated with pulmonary exacerbations in 
children with cystic fibrosis. Ann Am Thorac Soc 11:198-204. https://doi.org/10.1513/AnnalsATS.201208-068OC

48. Boyle MP, Noschese ML, Watts SL et al (2005) Failure of highdose ergocalciferol to correct vitamin D deficiency in adults with cystic fibrosis. Am J Respir Crit Care Med 172:212-217. https:// doi.org/10.1164/rccm.200403-3870C

49. Wani WA, Nazir M, Bhat JI et al (2019) Vitamin D status correlates with the markers of cystic fibrosis-related pulmonary disease. Pediatr Neonatol 60:210-215. https://doi.org/10.1016/j. pedneo.2018.07.001

50. Vanstone MB, Egan ME, Zhang JH, Carpenter TO (2015) Association between serum 25-hydroxyvitamin D level and pulmonary exacerbations in cystic fibrosis. Pediatr Pulmonol 50:441446. https://doi.org/10.1002/ppul.23161

51. Timmers NKLM, Stellato RK, van der Ent CK et al (2019) Vitamin D intake, serum 25-hydroxy vitamin D and pulmonary function in paediatric patients with cystic fibrosis: a longitudinal approach. Br J Nutr 121:195-201. https://doi.org/10.1017/S0007 114518003021

52. Green D, Carson K, Leonard A et al (2008) Current treatment recommendations for correcting vitamin $\mathrm{D}$ deficiency in pediatric patients with cystic fibrosis are inadequate. J Pediatr 153:554-559. https://doi.org/10.1016/j.jpeds.2008.04.058

53. Sexauer WP, Hadeh A, Ohman-Strickland PA et al (2015) Vitamin D deficiency is associated with pulmonary dysfunction in cystic fibrosis. J Cyst Fibros 14:497-506. https://doi. org/10.1016/j.jcf.2014.12.006

54. Wolfenden LL, Judd SE, Shah R et al (2008) Vitamin D and bone health in adults with cystic fibrosis. Clin Endocrinol 69:374-381. https://doi.org/10.1111/j.1365-2265.2008.03216 $\mathrm{x}$

55. Oliveira MS, Matsunaga NY, Rodrigues MLE et al (2019) Lung disease and vitamin D levels in cystic fibrosis infants and preschoolers. Pediatr Pulmonol 54(5):563-574

56. Dubois CL, Labrèche E, Boudreau V et al (2018) Extra-skeletal impact of vitamin D supplementation protocol in an adult population with cystic fibrosis. Clin Nutr 38(4):1666-1671

57. Henderson RC, Lester G (1997) Vitamin D levels in children with cystic fibrosis. South Med J 90:378-383

58. Rovner AJ, Stallings VA, Schall JI et al (2007) Vitamin D insufficiency in children, adolescents, and young adults with cystic fibrosis despite routine oral supplementation. Am J Clin Nutr 86:1694-1699. https://doi.org/10.1093/ajcn/86.5.1694

59. Simoneau T, Bazzaz O, Sawicki GS, Gordon C (2014) Vitamin D status in children with cystic fibrosis. Associations with inflammation and bacterial colonization. Ann Am Thorac Soc 11:205-210. https://doi.org/10.1513/AnnalsATS.20130 6-171BC

60. Tangpricha V, Lukemire J, Chen Y et al (2019) Vitamin D for the immune system in cystic fibrosis (DISC): a double-blind, multicenter, randomized, placebo-controlled clinical trial. Am J Clin Nutr 109:544-553. https://doi.org/10.1093/ajcn/nqy291

61. Grossmann RE, Zughaier SM, Kumari M et al (2012) Pilot study of vitamin D supplementation in adults with cystic fibrosis pulmonary exacerbation: a randomized, controlled trial. Dermatoendocrinol 4:191-197. https://doi.org/10.4161/derm.20332

62. DiFranco KM, Mulligan JK, Sumal AS, Diamond G (2017) Induction of CFTR gene expression by $1,25(\mathrm{OH}) 2$ vitamin D3, $25 \mathrm{OH}$ vitamin D3, and vitamin D3 in cultured human airway epithelial cells and in mouse airways. J Steroid Biochem Mol Biol 173:323-332. https://doi.org/10.1016/j.jsbmb.2017.01.013

63. Pincikova T, Svedin E, Domsgen E et al (2016) Cystic fibrosis bronchial epithelial cells have impaired ability to activate vitamin D. Acta Paediatr Oslo Nor 105:851-853. https://doi.org/10.1111/ apa.13361
64. McNally P, Coughlan C, Bergsson G et al (2011) Vitamin D receptor agonists inhibit pro-inflammatory cytokine production from the respiratory epithelium in cystic fibrosis. J Cyst Fibros 10:428-434. https://doi.org/10.1016/j.jcf.2011.06.013

65. Yim S, Dhawan P, Ragunath C et al (2007) Induction of cathelicidin in normal and CF bronchial epithelial cells by 1,25-dihydroxyvitamin $\mathrm{D}(3)$. J Cyst Fibros 6:403-410. https://doi. org/10.1016/j.jcf.2007.03.003

66. Pincikova T, Paquin-Proulx D, Sandberg JK et al (2017) Clinical impact of vitamin D treatment in cystic fibrosis: a pilot randomized, controlled trial. Eur J Clin Nutr 71:203-205. https://doi. org/10.1038/ejen.2016.259

67. Alvarez JA, Chong EY, Walker DI et al (2017) Plasma metabolomics in adults with cystic fibrosis during a pulmonary exacerbation: a pilot randomized study of high-dose vitamin D3 administration. Metabolism 70:31-41. https://doi.org/10.1016/j.metab ol.2017.02.006

68. Vestbo J, Hurd SS, Agustí AG et al (2013) Global strategy for the diagnosis, management, and prevention of chronic obstructive pulmonary disease: GOLD executive summary. Am J Respir Crit Care Med 187:347-365. https://doi.org/10.1164/rccm.20120 4-0596PP

69. Kim V, Aaron SD (2018) What is a COPD exacerbation? Current definitions, pitfalls, challenges and opportunities for improvement. Eur Respir J 52(5):1801261

70. Janssens W, Mathieu C, Boonen S, Decramer M (2011) Vitamin D deficiency and chronic obstructive pulmonary disease: a vicious circle. Vitam Horm 86:379-399. https://doi. org/10.1016/B978-0-12-386960-9.00017-4

71. Kokturk N, Baha A, Oh Y-M et al (2018) Vitamin D deficiency: what does it mean for chronic obstructive pulmonary disease (COPD)? a compherensive review for pulmonologists. Clin Respir J 12:382-397. https://doi.org/10.1111/crj.12588

72. Jolliffe DA, James WY, Hooper RL et al (2018) Prevalence, determinants and clinical correlates of vitamin D deficiency in patients with chronic obstructive pulmonary disease in London, UK. J Steroid Biochem Mol Biol 175:138-145. https:// doi.org/10.1016/j.jsbmb.2017.01.019

73. Ferrari R, Caram LMO, Tanni SE et al (2018) The relationship between Vitamin D status and exacerbation in COPD patients-a literature review. Respir Med 139:34-38. https:// doi.org/10.1016/j.rmed.2018.04.012

74. Zhu M, Wang T, Wang C, Ji Y (2016) The association between vitamin D and COPD risk, severity, and exacerbation: an updated systematic review and meta-analysis. Int J Chron Obstruct Pulmon Dis 11:2597-2607. https://doi.org/10.2147/ COPD.S101382

75. Malinovschi A, Masoero M, Bellocchia M et al (2014) Severe vitamin $\mathrm{D}$ deficiency is associated with frequent exacerbations and hospitalization in COPD patients. Respir Res 15:131. https ://doi.org/10.1186/s12931-014-0131-0

76. Mekov E, Slavova Y, Tsakova A et al (2015) Vitamin D deficiency and insufficiency in hospitalized COPD patients. PLoS ONE 10:e0129080. https://doi.org/10.1371/journal.pone.01290 80

77. Quint JK, Donaldson GC, Wassef N et al (2012) 25-hydroxyvitamin D deficiency, exacerbation frequency and human rhinovirus exacerbations in chronic obstructive pulmonary disease. BMC Pulm Med 12:28. https://doi. org/10.1186/1471-2466-12-28

78. Puhan MA, Siebeling L, Frei A et al (2014) No association of 25-hydroxyvitamin $\mathrm{D}$ with exacerbations in primary care patients with COPD. Chest 145:37-43. https://doi.org/10.1378/chest $.13-1296$

79. Jung JY, Kim YS, Kim SK et al (2015) Relationship of vitamin D status with lung function and exercise capacity in COPD. 
Respirol Carlton Vic 20:782-789. https://doi.org/10.1111/ resp. 12538

80. Persson LJP, Aanerud M, Hiemstra PS et al (2015) Vitamin $\mathrm{D}$, vitamin $\mathrm{D}$ binding protein, and longitudinal outcomes in COPD. PLoS ONE 10:e0121622. https://doi.org/10.1371/journ al.pone. 0121622

81. Kunisaki KM, Niewoehner DE, Connett JE, COPD Clinical Research Network (2012) Vitamin D levels and risk of acute exacerbations of chronic obstructive pulmonary disease: a prospective cohort study. Am J Respir Crit Care Med 185:286-290. https://doi.org/10.1164/rccm.201109-1644OC

82. Crisafulli E, Barbeta E, Ielpo A, Torres A (2018) Management of severe acute exacerbations of COPD: an updated narrative review. Multidiscip Respir Med 13:36. https://doi.org/10.1186/ s40248-018-0149-0

83. Lehouck A, Mathieu C, Carremans C et al (2012) High doses of vitamin $\mathrm{D}$ to reduce exacerbations in chronic obstructive pulmonary disease: a randomized trial. Ann Intern Med 156:105-114. https://doi.org/10.7326/0003-4819-156-2-201201170-00004

84. Martineau AR, James WY, Hooper RL et al (2015) Vitamin D3 supplementation in patients with chronic obstructive pulmonary disease (ViDiCO): a multicentre, double-blind, randomised controlled trial. Lancet Respir Med 3:120-130. https://doi. org/10.1016/S2213-2600(14)70255-3

85. Zendedel A, Gholami M, Anbari K et al (2015) Effects of vitamin D intake on FEV1 and COPD exacerbation: a randomized clinical trial study. Glob J Health Sci 7:243-248. https://doi. org/10.5539/gjhs.v7n4p243

86. Jolliffe DA, Greenberg L, Hooper RL et al (2019) Vitamin D to prevent exacerbations of COPD: systematic review and metaanalysis of individual participant data from randomised controlled trials. Thorax 74:337-345. https://doi.org/10.1136/thora xjnl-2018-212092

87. Gold DR, Litonjua AA, Carey VJ et al (2016) Lung VITAL: rationale, design, and baseline characteristics of an ancillary study evaluating the effects of vitamin D and/or marine omega-3 fatty acid supplements on acute exacerbations of chronic respiratory disease, asthma control, pneumonia and lung function in adults. Contemp Clin Trials 47:185-195. https://doi. org/10.1016/j.cct.2016.01.003

88. Rafiq R, Aleva FE, Schrumpf JA et al (2015) Prevention of exacerbations in patients with COPD and vitamin D deficiency through vitamin D supplementation (PRECOVID): a study protocol. BMC Pulm Med 15:106. https://doi.org/10.1186/s1289 0-015-0101-4

89. Cohen-Lahav M, Shany S, Tobvin D et al (2006) Vitamin D decreases NFkappaB activity by increasing IkappaBalpha levels. Nephrol Dial Transplant 21:889-897. https://doi.org/10.1093/ ndt/gfi254

90. Zhang Y, Leung DYM, Richers BN et al (2012) Vitamin D inhibits monocyte/macrophage proinflammatory cytokine production by targeting MAPK phosphatase-1. J Immunol Baltim Md 188:2127-2135. https://doi.org/10.4049/jimmunol.1102412

91. Yang H, Long F, Zhang Y et al (2015) $1 \alpha, 25$-Dihydroxyvitamin D3 induces neutrophil apoptosis through the p38 MAPK signaling pathway in chronic obstructive pulmonary disease patients. PLoS ONE 10:e0120515. https://doi.org/10.1371/journ al.pone. 0120515

92. Spira-Cohen A, Chen LC, Kendall M et al (2011) Personal exposures to traffic-related air pollution and acute respiratory health among Bronx schoolchildren with asthma. Environ Health Perspect 119:559-565. https://doi.org/10.1289/ehp.1002653

93. Ali NS, Nanji K (2017) A review on the role of vitamin D in asthma. Cureus 9:e1288. https://doi.org/10.7759/cureus.1288
94. Brehm JM, Schuemann B, Fuhlbrigge AL et al (2010) Serum vitamin D levels and severe asthma exacerbations in the Childhood Asthma Management Program study. J Allergy Clin Immunol 126:52-58.e5. https://doi.org/10.1016/j.jaci.2010.03.043

95. Jat KR, Khairwa A (2017) Vitamin D and asthma in children: a systematic review and meta-analysis of observational studies. Lung India 34:355-363. https://doi.org/10.4103/09702113.209227

96. Wagner CL, Hollis BW (2018) The implications of Vitamin D status during pregnancy on mother and her developing child. Front Endocrinol 9:500. https://doi.org/10.3389/fendo .2018.00500

97. Yawn J, Lawrence LA, Carroll WW, Mulligan JK (2015) Vitamin $\mathrm{D}$ for the treatment of respiratory diseases: is it the end or just the beginning? J Steroid Biochem Mol Biol 148:326-337. https ://doi.org/10.1016/j.jsbmb.2015.01.017

98. Bozzetto S, Carraro S, Giordano G et al (2012) Asthma, allergy and respiratory infections: the vitamin D hypothesis. Allergy 67:10-17. https://doi.org/10.1111/j.1398-9995.2011.02711.x

99. Lima JJ, Castro M, King TS et al (2018) Association of free vitamin D3 concentrations and asthma treatment failures in the VIDA Trial. Ann Allergy Asthma Immunol 121:444-450.e1. https://doi.org/10.1016/j.anai.2018.06.001

100. Bugadze L, Manjavidze N, Jorjoliani L (2018) Asthma control status and lung function in relation to vitamin d level in children with bronchial asthma. Georgian Med News 283:115-118

101. Searing DA, Zhang Y, Murphy JR et al (2010) Decreased serum vitamin D levels in children with asthma are associated with increased corticosteroid use. J Allergy Clin Immunol 125:9951000. https://doi.org/10.1016/j.jaci.2010.03.008

102. Confino-Cohen R, Brufman I, Goldberg A, Feldman BS (2014) Vitamin D, asthma prevalence and asthma exacerbations: a large adult population-based study. Allergy 69:1673-1680. https://doi. org/10.1111/all.12508

103. Salas NM, Luo L, Harkins MS (2014) Vitamin D deficiency and adult asthma exacerbations. J Asthma 51:950-955. https://doi. org/10.3109/02770903.2014.930883

104. Gupta A, Sjoukes A, Richards D et al (2011) Relationship between serum vitamin $\mathrm{D}$, disease severity, and airway remodeling in children with asthma. Am J Respir Crit Care Med 184:1342-1349. https://doi.org/10.1164/rccm.201107-1239OC

105. Brehm JM, Acosta-Pérez E, Klei L et al (2012) Vitamin D insufficiency and severe asthma exacerbations in Puerto Rican children. Am J Respir Crit Care Med 186:140-146. https://doi. org/10.1164/rccm.201203-04310C

106. Boonpiyathad T, Chantveerawong T, Pradubpongsa P, Sangasapaviliya A (2016) Serum vitamin D levels and vitamin D supplement in adult patients with asthma exacerbation. J Allergy 2016:4070635. https://doi.org/10.1155/2016/4070635

107. Rosser F, Brehm JM, Forno E et al (2014) Proximity to a major road, vitamin D insufficiency, and severe asthma exacerbations in Puerto Rican children. Am J Respir Crit Care Med 190:1190 1193. https://doi.org/10.1164/rccm.201408-1568LE

108. Busse WW (2019) Biological treatments for severe asthma: a major advance in asthma care. Allergol Int 68:158-166. https:// doi.org/10.1016/j.alit.2019.01.004

109. Fares MM, Alkhaled LH, Mroueh SM, Akl EA (2015) Vitamin D supplementation in children with asthma: a systematic review and meta-analysis. BMC Res Notes 8:23. https://doi.org/10.1186/ s13104-014-0961-3

110. Luo J, Liu D, Liu C-T (2015) Can vitamin D supplementation in addition to asthma controllers improve clinical outcomes in patients with asthma?: a meta-analysis. Medicine 94:e2185. https ://doi.org/10.1097/MD.0000000000002185 
111. Martineau AR, Cates CJ, Urashima M et al (2016) Vitamin D for the management of asthma. Cochr Database Syst Rev. https ://doi.org/10.1002/14651858.CD011511.pub2

112. Jolliffe DA, Greenberg L, Hooper RL et al (2017) Vitamin D supplementation to prevent asthma exacerbations: a systematic review and meta-analysis of individual participant data. Lancet Respir Med 5:881-890. https://doi.org/10.1016/S2213 -2600(17)30306-5

113. Wang M, Liu M, Wang C et al (2019) Association between vitamin D status and asthma control: a meta-analysis of randomized trials. Respir Med 150:85-94. https://doi.org/10.1016/j. rmed.2019.02.016

114. Kaaviyaa AT, Krishna V, Arunprasath TS, Ramanan PV (2018) Vitamin D deficiency as a factor influencing asthma control in children. Indian Pediatr 55:969-971

115. Mirzakhani H, Carey VJ, Zeiger R et al (2019) Impact of parental asthma, prenatal maternal asthma control, and vitamin D status on risk of asthma and recurrent wheeze in 3-year-old children. Clin Exp Allergy 49:419-429. https://doi.org/10.1111/cea.13320

116. Nanzer AM, Chambers ES, Ryanna K et al (2013) Enhanced production of IL-17A in patients with severe asthma is inhibited by $1 \alpha, 25$-dihydroxyvitamin D3 in a glucocorticoid-independent fashion. J Allergy Clin Immunol 132:297-304.e3. https://doi. org/10.1016/j.jaci.2013.03.037

117. Lan N, Luo G, Yang X et al (2014) 25-Hydroxyvitamin D3-deficiency enhances oxidative stress and corticosteroid resistance in severe asthma exacerbation. PLoS ONE 9:e111599. https://doi. org/10.1371/journal.pone.0111599
118. Ramos-Martínez E, López-Vancell MR, Fernández de CórdovaAguirre JC et al (2018) Reduction of respiratory infections in asthma patients supplemented with vitamin D is related to increased serum IL-10 and IFN $\gamma$ levels and cathelicidin expression. Cytokine 108:239-246. https://doi.org/10.1016/j. cyto.2018.01.001

119. Alansari K, Davidson BL, Yousef KI et al (2017) Rapid versus maintenance vitamin D supplementation in deficient children with asthma to prevent exacerbations. Chest 152:527-536. https ://doi.org/10.1016/j.chest.2017.06.021

120. Martineau AR, Jolliffe DA, Hooper RL et al (2017) Vitamin D supplementation to prevent acute respiratory tract infections: systematic review and meta-analysis of individual participant data. BMJ 356:i6583. https://doi.org/10.1136/bmj.i6583

121. Leyssens C, Verlinden L, Verstuyf A (2014) The future of vitamin D analogs. Front Physiol 5:122. https://doi.org/10.3389/ fphys.2014.00122

122. Obi Y, Hamano T, Isaka Y (2015) Prevalence and prognostic implications of vitamin D deficiency in chronic kidney disease. Dis Markers 2015:868961. https://doi.org/10.1155/2015/868961

Publisher's Note Springer Nature remains neutral with regard to jurisdictional claims in published maps and institutional affiliations. 